\title{
Elogio al obispo Antonio Tavira de Bernardo Cólogan. Edición crítica de la obra y su traducción al castellano ${ }^{1}$
}

\author{
Carolina REAL TORRES \\ Universidad de La Laguna \\ carrel@ull.edu.es
}

Recibido: 13 de septiembre de 2013

Aceptado: 9 de marzo de 2014

\section{RESUMEN}

Durante el siglo XVIII en Canarias destacan importantes personajes de una gran conciencia humanística y clásica, entre ellos Bernardo Cólogan Fallon, una figura clave en el panorama cultural de Tenerife, cuya labor en la vida social, política e intelectual contribuyó en gran manera a la difusión de las ideas ilustradas en las Islas. Nuestro objetivo es contribuir a un mayor conocimiento de su faceta literaria en el marco de la ilustración canaria y rescatar del olvido una de sus obras escrita en latín mediante una nueva edición crítica y su traducción.

Palabras clave: Humanismo. Canarias. Tavira. Cólogan.

Real Torres, C., «Elogio al obispo Antonio Tavira de Bernardo Cólogan. Edición critica de la obra y su traducción al castellano», Cuad. Fil. Clás. Estud. Lat. 34.1 (2014) 111-130.

Praise to the Bishop Antonio Tavira by Bernardo Cólogan. Critical edition of the work and his translation to the Castilian

\begin{abstract}
During the eighteenth century Canary major characters include a classical and humanistic conscience, including Bernardo Cólogan Fallon, a key figure in the cultural landscape of Tenerife, whose work in social, political and intellectual contributed greatly to the spread of Enlightenment ideas in the Islands. Our goal is to contribute to a better understanding of his literary facet under Canarian illustration and to rescue from oblivion one of his works written in Latin, by a new critical edition and translation.
\end{abstract}

Keywords: Humanism. Canary Islands. Tavira. Cólogan.

Real Torres, C., «Praise to the Bishop Antonio Tavira by Bernardo Cólogan. Critical edition of the work and his translation to the Castilian», Cuad. Fil. Clás. Estud. Lat. 34.1 (2014) 111-130.

Sumario: 1 . Sobre el autor. 2. Sobre su obra. 3. Edición crítica. 4. Traducción al castellano. 5. Epílogo. 6. Referencias bibliográficas.

\footnotetext{
${ }^{1}$ Agradecemos al doctor Don Tomás González Rolán las múltiples ideas y sugerencias que han posibilitado la realización de este artículo.
} 


\section{SOBRE EL AUTOR}

En el siglo XVIII se erigirá en las Islas Canarias una nueva generación con importantes personajes como Gordillo (1773), Murphy (1774) o Graciliano Afonso (1775), que mantendrán una gran erudición por el saber clásico. Su intención será preservar la cultura clásica y expresar a través de ella la tradición canaria dentro de la realidad del momento. A lo largo de la historia muchos de ellos serán reconocidos y es nuestra intención reconocer la obra de Bernardo Cólogan Fallon, poeta, dramaturgo, filántropo, amigo de la sabiduría y autor de varias obras de interés para el estudio de la tradición clásica.

Bernardo Tomás José María de los Remedios Cólogan Fallon nació en el Puerto de la Cruz de La Orotava en la isla de Tenerife el 8 de septiembre de 1772 (Álvarez 2008, pp.249-250; Guimerá 1992, p.212 y 1979, pp.309-310). Como hijo primogénito del matrimonio formado por Tomás Cólogan Valois e Isabel Fállon de Gante, pertenece a la tercera generación de la familia Cólogan, la casa comercial irlandesa más importante de la colonia británica en el Puerto de la Cruz durante los siglos XVII y XVIII. Fue, por tanto, miembro señalado de la burguesía comercial portuense que destacó por su implicación en la política y en la vida cultural de la isla ${ }^{2}$, pues no sólo el comercio sino también la acción política y social fueron otros espacios en el que hubo de implicarse ${ }^{3}$.

Desde joven actuó intensamente en la vida pública dentro del Ayuntamiento de su Puerto natal, pues ya, a los veintisiete años, obtuvo su primer cargo al resultar elegido síndico personero ${ }^{4}$. Fue también Alcalde Real del Puerto (1804-1805), Alcalde del Agua (1807-1808), miembro de la Junta Gubernativa de Tenerife (1808-1809) y, de nuevo, Síndico Personero (1810). Durante su mandato tuvo lugar el famoso motín contra los franceses (13 de marzo de 1810), en el cual Cólogan se vería implicado y durante el cual cayeron asesinados su escribiente Josef Bressan y el maestro de Letras

${ }^{2}$ Cf. Guimerá (1992, p.199): «La familia irlandesa de los Cólogan, arraigada en la Isla de Tenerife y concretamente en el Puerto de la Orotava desde mediados del siglo XVIII, ha dado a la vida pública de este pueblo, a partir de la primera generación tinerfeña, hasta seis alcaldes; varios de ellos desempeñando el cargo en distintas ocasiones, a lo largo de casi un siglo, honrando así a su misma cuna».

${ }^{3}$ Los antepasados de Cólogan habían emigrado a España y, luego, a Canarias, al amparo de una monarquía católica que permitía el acceso al comercio con las Américas a través de sus colonias. Felipe V había concedido como premio a su apoyo numerosos privilegios a los católicos irlandeses. Por su parte, las Islas Canarias tenían un gran potencial exportador -especialmente el Puerto de la Cruz- para la producción de vinos, principal actividad de la casa comercio Cólogan. Igualmente sus antepasados fueron mecenas de artistas y promotores del arte y la educación en las Islas, así como destacados políticos locales, lo que los distinguen también en el campo de la acción social y cultural. Cf. Álvarez (2008, pp.52-52); Guimerá (1979, pp.202, 307-309); Régulo (1952, pp.280-285). Sobre Bernardo Cólogan y su familia, cf. Cólogan (2010).

${ }^{4}$ Cf. Álvarez (2008, pp.254-255): «El año 1800 el pueblo le nombró su síndico personero y para el de 1804 alcalde real, en cuyo ministerio se condujo con tanta satisfacción pública que le reeligieron para el siguiente 1805, cosa prohibida por la ley. Pero, habiendo representado el personero y el pueblo a la Real Audiencia encomiando los muchos beneficios que Cólogan había hecho y los más que se prometían de su patriotismo y su munificencia, el Tribunal disimuló atendiendo a la conveniencia pública. Efectivamente, fueron muy importantes las mejoras civiles de todo género practicadas por Cólogan en su bienio, en cuya persecución gastó más de 600 pesos corrientes de su caudal» (Guimerá 1992, p.14). 
y Música Luis Beltrán Broual, regidor de la Escuela creada por el propio Cólogan en la casa de su propiedad ${ }^{5}$.

A partir de este momento, la trayectoria de Cólogan discurrirá entre un paulatino protagonismo público y el desarrollo de su vocación literaria y artística. Bernardo Cólogan es el típico ilustrado, con sus inquietudes docentes y científicas, un hombre culto, emprendedor y cosmopolita, resultado, sin lugar a dudas, de su excelente educación en Francia, Holanda e Inglaterra (Guimerá 1979, p.310; 1992, pp.212-213). Durante sus estancias en el extranjero, había tenido la oportunidad de conocer a importantes personajes, como es el caso de Saint Cir, mariscal del imperio francés, su condiscípulo en el Colegio de Navarra en París (Álvarez 2008, p.250).

Tras su regreso al Puerto en 1793, Cólogan quiso, desde un principio, apartarse del negocio familiar, pues su vocación e ideales le impulsaban a descubrir horizontes más lejanos. Su sólida formación y una curiosidad científica innata le llevaron a ocupar un importante papel como referente social y cultural de la época. Fue miembro de la Real Sociedad Económica de Amigos del País de Tenerife, asiduo de tertulias literarias y siempre amigo de prestar su ayuda desinteresadamente. Al igual que su tío, Bernardo Cólogan Valois, cuya casa siempre estuvo abierta a viajeros de todas las nacionalidades, nuestro autor tuvo estrechas relaciones con los viajeros científicos que visitaron Tenerife en la segunda mitad del siglo XVIII, a los que siempre recibió con hospitalidad, como es el caso de Humboldt, Aimé Bonpland, Andrés Pedro Ledru o Bory de Saint Vincent. Al primero le proporcionó sus dibujos y anotaciones sobre la erupción del volcán de Chahorra, alias Venge o Taucho, en $1798^{6}$, que él mismo había inspeccionado acompañado de otros jóvenes del Puerto. Bory de Saint Vincent consideró digno de transcribir su relato y así lo hizo años más tarde en su Ensayo sobre las Afortunadas. El informe de Cólogan se publicaría parcialmente, siglo y cuarto más tarde, en la Arautápala, periódico del Puerto de la $\mathrm{Cruz}^{7}$.

\section{SOBRE SU OBRA}

La obra que nos ocupa apenas ha tenido relevancia en los manuales de literatura, tampoco ha sido abordada desde un punto de vista literario o histórico, por lo que consideramos necesario un estudio exhaustivo desde el punto filológico, consistente en una nueva edición y una traducción al castellano a fin de contribuir a un mayor conocimiento del autor y a una mayor difusión de su obra.

\footnotetext{
${ }^{5}$ Fue Cólogan protagonista de una labor humanitaria en su actuación en favor del pueblo canario (Guimerá 1992, p.218 y 1979, pp.340-342; Martín 2012).

${ }^{6} C f$. Álvarez (2008, p.53): «A Humboldt le despertó gran admiración por su cultura, y, como a Bory de Saint Vincent, le suministró sus manuscritos sobre los terremotos y sobre la erupción volcánica de Chahorra de 1798». Cf. Álvarez (2008, pp.253-254); Guimerá (1992, pp.213-214).

${ }^{7}$ Arautápala, «Erupciones volcánicas habidas en Tenerife desde la conquista hasta nuestros días», núm. 91, sábado 27 de noviembre de 1909. Cf. Guimerá (1979, pp.323-324). Ha sido editada en su totalidad en fechas recientes en Romero Ruiz (1991, pp.571-575).
} 
Su contextualización dentro del panorama cultural que marcaba el siglo XVIII en Canarias para la producción literaria en lengua latina es fruto de la admiración que Cólogan sentía por los clásicos, así como de sus estudios en latín, lengua que manejaba a la perfección ${ }^{8}$. Y en latín compuso este poema en hexámetros como laudatio a un personaje que representa el mejor impulso ilustrado que han conocido las islas, el obispo don Antonio Tavira y Almazán, cuyo proyecto de modernización ha sido alabado por la crítica ${ }^{9}$. En este contexto, la actividad cultural y económica estaba en estrecha relación con los intereses intelectuales de los obispos, quienes destacaron por sus proyectos de reforma para la enseñanza, especialmente Tavira, para quien la educación era su prioridad (Galván 2010, p.187). En el plano de las ideas, Tavira apoyó los principios básicos de la fe cristiana, rechazando el lujo y las supersticiones, apoyó las nuevas corrientes del pensamiento en cuestiones pedagógicas, el acceso a la cultura para las clases populares y la lectura de libros no permitidos, por lo que fue tachado de jansenista (Álvarez 2008, p.149); Saugnieux 1986).

Si del obispo hay abundantes noticias sobre su programa reformista, de Cólogan sólo teníamos hasta la fecha sucintas referencias a su labor local en el Puerto de la Cruz. El «Elogio» que dedica a Tavira permite comprobar que la agenda ilustrada del religioso es uno de los principales acicates (quizás su inspiración) para el político y comerciante de origen irlandés.

Antonio Tavira y Almazán, obispo de Canarias (1791-1796), era una de las figuras más controvertidas del reformismo católico de la época y, por ello, motivo de admiración para el joven Cólogan. Cuando, en junio de 1795, dentro de su intensa agenda pastoral por las islas ${ }^{10}$, Tavira visita el Puerto de la Cruz, localidad portuaria que aún recibía el nombre de Puerto de la Orotava, Cólogan ve la ocasión de pedirle su ayuda en favor de la instrucción pública en la provincia ${ }^{11}$, por la que él mismo

${ }^{8}$ Cf. Galván (2010, p.190): «En el período que nos ocupa, la vida literaria y cultural, como corresponde al perfil habitual de la Ilustración, es netamente elitista, circunscrita a una minoría representada por el clero, la nobleza, los altos funcionarios, los militares o los comerciantes».

9 Antonio Tavira y Almazán (1791-1796) ocupó la mitra canariense durante el reinado de Carlos IV. Cf. Galván (2010, p.186); Infantes (1979, pp.24-25).

${ }^{10}$ Cf. Saugnieux (1986, p.48): «En Canarias se dedicó a visitar todos los pueblos de las diferentes islas sin exceptuar ninguno, obra considerable, que suponía cantidad de fatigas y hasta de peligros, pero que dio ocasión al nuevo obispo de afirmar sus propias concepciones en material de disciplina eclesiástica y de mostrar su celo pastoral». Cf. Cazorla (1997, p.340); Barrios (2002, p.56).

${ }^{11}$ El historiador José Agustín Álvarez Rixo nos habla así de esta visita: «Llegado el mes de junio estuvo en visita pastoral el Ilustrísimo Señor don Antonio Tavira y Almarán, Obispo de estas islas, sujeto muy distinguido por su sabiduría. Advirtió lo poco decorados que estaban algunos de los altares del cuerpo de nuestra parroquia, mandó a sus dueños que lo reformasen y como no lo hicieron se quitaron. El uno de ellos era un solo cajón con una imagen dentro. Su Ilustrísima visitó la escuela de primeras letras que daba gratis el Presbítero don Juan Agustín de Chaves en la calle del Norte, donde vivía, número 40, a quien aprobó su caritativa ocupación entregándole cincuenta pesos corrientes para que repartiese con los discípulos pobres, lo cual se verificó desde luego. Asimismo le dijo: señor Chaves, puesto que usted es un hombre ingenioso y entiende de libros, le doy el encargo de que los forme para la colecturía de esta parroquia, por no estar los antiguos con el esmero que corresponde. Dicho don Juan que era colector, encuadernó los que desde aquella fecha sirvieron en la iglesia que parece que fueron costeados por el propio ilustre prelado, quien en otras varias determinaciones dio a conocer sus sentimientos cristianos y filantrópicos». 
tanto abogaba. La afinidad ideológica que sentía por el obispo le anima a componer y dedicarle este poema en su onomástica, el 13 de junio, con motivo del encargo de establecer la Universidad que Tavira había recibido. Cólogan era en ese momento un joven de veintitrés años, muy comprometido con la vida cultural de la ciudad (organización de grupos poéticos, sesiones festivo-teatrales, veladas musicales, etc.), pero aún con escaso relieve en la vida pública de la misma (Álvarez 2008, p.252; Martín 2012, p.874).

Su afán de renovación, similar al proyecto de Tavira, le lleva a lamentarse en sus versos de la despreocupación por la cultura y de la inexistencia de escuelas públicas en el Puerto de su época, por lo que él mismo contribuye con su dinero a construir colegios y bibliotecas ${ }^{12}$. Hizo traer de la Península ejemplares de diversas obras para difundir el gusto por la literatura, y el Diccionario y la Gramática Castellana que desde ese momento empezó a usarse ${ }^{13}$. De su inmensa colección de libros se deduce que era un apasionado de la nación y la literatura francesa, lo cual es sintomático del ambiente cultural que circundaba. Su biblioteca es fruto de sus inquietudes intelectuales y reflejo de su mente ilustrada y cosmopolita. En ella las ediciones de autores clásicos grecolatinos, humanistas, libros en latín, inglés, francés, holandés y español, manuales de gramática, etc., además de un copioso archivo musical, son de una gran riqueza. No sólo muchas son primeras ediciones, sino también otras están consideradas verdaderas joyas bibliográficas (Guimerá 1979, p.311).

Cólogan, en su apuesta por una enseñanza gratuita, financia la creación de escuelas, costeando todo lo necesario para su establecimiento y formando un plan que pudiese asegurar su estabilidad mediante la manutención de pobres, donación de libros y mobiliario, y dotación de maestros (Álvarez 2008, p.24; Guimerá 1992, p.215). Su actuación por el bien público abarca también el empedrado de calles y caminos (Álvarez 2008, p.255; Guimerá 1992, p.216), la mejora del censo y la caridad con enfermos y necesitados ${ }^{14}$. Cuando en 1811 se propaga la epidemia de fiebre amarilla o

Entonces el joven don Bernardo Cólogan Fallon, sensible a los merecimientos de este excelente varón, escribió un poemita latino en su elogio, sobre todo por el deseo de propagar la instrucción pública asaz descuidada en nuestro país» (Álvarez, 1994, pp.145-146). Cf. Guimerá (1979, p.314).

${ }^{12} C f$. Galván (2010, p.188): «Prueba de su preocupación por los libros y la lectura fue la donación que efectuó al abandonar la mitra canaria a la biblioteca del Seminario y de la Universidad de San Fernando en Tenerife. También intercedió ante las restricciones reales por las peticiones de fondos que hiciera el bibliotecario Antonio Raymond para la mejora de la biblioteca pública». Sobre la biblioteca de Tavira y su incidencia en la enseñanza humanística en Canarias: Salas (1999, pp.264-266; 2000; Infantes (1981).

${ }^{13} C f$. Álvarez (2008, p.250): «En medio de sus tareas no olvidó don Bernardo el gusto que había adquirido por las ciencias y bellas artes, las cuales tenía oportunidad de cultivar por medio de los buenos libros que hacía venir de Europa, como los que había ya en su biblioteca acopiados por algunos de sus progenitores que también había sido instruidos; y por el trato con distintos viajeros filósofos ilustres que siempre venían recomendados a su casa».

${ }^{14} C f$. Álvarez (2008, pp.251-252): «La noche 24 de julio de 1797 asaltaron los ingleses la plaza de Santa Cruz, de donde fueron rechazados; y al amanecer del 25 consta se hallaba allí el joven Cólogan empleando su genio benéfico en curar las heridas de nuestros campeones y de los enemigos esparcidos promiscuamente por nuestras calles. Y cuando ya no tenía vendas ni pañuelos rasgó su propia camisa para que sirviese de vendajes. No ha quedado esta acción olvidada porque el historiador de las Canarias don José de Viera en su famosa oda escrita con motivo de tan heroico acontecimiento dice en su estrofa 27: 
vómito prieto, que alarmó y consternó a todas las islas, no duda en socorrer al pueblo con alimentos y proporcionarles de manera gratuita la vacuna ${ }^{15}$.

Su filantropía y su amor por las artes lo convierten en mecenas de artistas y literatos. Su casa estuvo abierta a tertulias, veladas musicales y representaciones teatrales en las que él mismo participaba. Ya su familia había sido precursora del gran movimiento teatral desarrollado en el Puerto, financiando espectáculos y formando grupos de teatro (Ramos 2008, p.29).

Su producción literaria en latín, olvidada y desconocida por muchos, forma parte de la estética ilustrada del momento cuyo rector era la imitación de los clásicos y el uso de su lengua como instrumento de cultura ${ }^{16}$. Escribir en latín era su manera de rendir tributo a nuestros autores grecolatinos.

\section{EDICIÓN CRÍTICA}

Ya anunciábamos (Real, e.p.) en el V Congreso Internacional de Humanismo y pervivencia del mundo clásico (Alcañiz, 2010) nuestro proyecto de edición crítica de la producción en lengua latina de Bernardo Cólogan Fallon, un proyecto ambicioso, a lo largo del cual hemos hallado esta obra de singular importancia, de la cual se conservan un manuscrito y tres copias impresas.

El manuscrito se encuentra en una colección poética realizada por Antonio Pereyra Pacheco ${ }^{17}$ y depositada actualmente en la Biblioteca de la Universidad de La Laguna: Ms. 67 Colección de varias poesías sagradas y profanas por distintos autores de las Islas Canarias. Reunidas por D. Antonio Pereyra Pacheco y Ruiz. S. XIX, t. $2^{\text {o18 }}$. Se trata de un manuscrito autógrafo impreso en el Instituto de Canarias por compra en 1866. El texto está anotado y con indicación de escansión en algunas palabras. Foliación antigua a tinta oscura y moderna a lápiz. Carece de filigranas y de

\section{Y hacer de actividad y patriotismo}

Un eminente empleo

Quintero, Cólogan, Creagh, Bataller, Feo»

15 Cf. Guimerá (1992, p.216): «En el año presente se han empedrado algunas calles, se han reedificado los paseos públicos y se han puesto transitable y cómodos los caminos que conducen al pueblo cuya obra aún sigue dicho Alcalde supliendo casi el todo del costo de sus propios haberes. El con éstos ha sostenido durante el tiempo de su Alcaldía la inoculación de la vacuna proporcionando por este medio la vacunación de los pobres; y en suma ... se ha presentado exponiendo sus intereses y facilitando el remedio que ha pendido de sus facultades. ...reparó los caminos de las salidas de este pueblo, y ..... ha propagado la vacuna y ha satisfecho los gastos de mantenerla entre los pobres, que ha fomentado el recurso pendiente en esa Real Audiencia a fin de poner este pueblo en una pie menos dependiente del de la Orotava persuadido de las ventajas que se habían de seguir a sus convecinos».

${ }^{16}$ Sobre el uso del latín en Canarias durante la Ilustración, $c f$. Domínguez (1989, p.164 s.).

${ }_{17}$ Antonio Pereira-Pacheco Ruiz (1790-1858), académico honorario de la Real Academia Canaria de Bellas artes y conocido por su labor de recopilación de documentos relativos a las Islas, continuó la breve Biblioteca de Autores Canarios, que había iniciado el historiador don José de Viera y Clavijo (Millares 1987).

${ }_{18}$ Universidad de La Laguna, Biblioteca, Catálogo de mss. de la Biblioteca Universitaria de La Laguna, 2002, pp.97-19. Ms. 67: Illustrissimo ac Dilectissimo D.D. Antonio de Tavira et Almazan, Canariensi Episcopo, Tertia decima Junii Sancti Antonii festiva die. Hoc carmen humillime offert Bernardus Cologan Fallon, ut Studia litteraria iam Regio concessa Decreto his in Insulis promoveat foveatque. 
cualquier elemento decorativo. Letra redonda, de trazo fino y elegante. Descripción física: 3v. (92f.; 209f.; 195f.: 21x15; 25x20; 20x15 cm). Se conserva en buen estado. Muestra algunas tachaduras y correcciones.

El ejemplar $B U$ (Biblioteca Universitaria de La Laguna) se localiza en el tomo 95 de Papeles Varios: Varias poesías a diferentes asuntos y en diferentes metros que ocupan treinta folios. Nacto permissu Lacuna Nivariensi: apud Michaelem Angelum Bazzanti, Regalis Societatis Typographum, 1795. Sign. C IV-7 P.V. 95. Es una edición a cargo de Miguel Ángel Bazzanti, impresor de la Real Sociedad Económica de Amigos del País de Tenerife. Está en malas condiciones de conservación, con manchas de humedad y borde de folios dentado ${ }^{19}$.

El ejemplar $R S$ (Real Sociedad Económica de Amigos del País) se halla en el Fondo Rodríguez Moure en el tomo Asuntos públicos y políticos desde 1695. Tomo III, Sign. RM 116 (20/37) f.42r-47r. La Laguna, 179520. Se trata también de una edición impresa a cargo de Miguel Ángel Bazzanti. Ejemplar con anotación manuscrita que indica su pertenencia a don Lópe Antonio de la Guerra y Peña ${ }^{21}$. Su estado de conservación es relativamente bueno.

El ejemplar $A A$ se encuentra en una colección privada perteneciente al Archivo Acialcázar de Las Palmas de Gran Canaria en un legajo (Legajo Obispado, siglo XVIII) de contenido misceláneo y sin numeración de páginas. En la portada figura a lápiz 87-1 (46.85). Contiene una anotación a tinta que se refiere al nombre del autor. Dicha nota está en la parte inferior y dice: Hijo del Puerto de la Cruz. Está en las peores condiciones de conservación, lo que ha dificultado su consulta.

Las dos primeras ediciones ( $B U$ y $R S$ ) salieron de la imprenta de Bazzanti poco después de que el poema fuera escrito. De la edición $A A$ desconocemos la fecha y lugar de impresión. No obstante, las tres copias son similares en cuanto al título, la disposición del texto y el mismo número de versos, con numeración hecha de cinco en cinco y puesta al margen, a excepción de los versos finales donde también se hace constar el verso 212 .

En el manuscrito puede observarse el mismo error que se repite en cada una de las ediciones en la numeración del texto, ya que el poema en cuestión consta de 207 versos escritos en hexámetros, y no de 212, como figura en los lugares citados ${ }^{22}$. Este error se debe a que del verso 90 se pasa a anotar el 100, dando como resultado cinco versos más.

Tras contrastar el texto del original manuscrito con las tres ediciones existentes, hemos llegado a la conclusión de que es necesario realizar una nueva edición de la

\footnotetext{
${ }^{19}$ Puede consultarse la reproducción digital del mismo en http://absysnet.bbtk.ull.es/cgi-bin/abnetopac/ O7097/ID344f3f3b/NT4.

${ }^{20}$ Illustrissimo ac Dilectissimo D.D. Antonio de Tavira et Almazan, Canariensi Episcopo, Tertia decima Junii Sancti Antonii festiva die. Hoc carmen humillime offert Bernardus Cologan Fallon, ut Studia litteraria iam Regio concessa Decreto his in Insulis promoveat foveatque. Anno Domini M.DCC.XCV. La Edición del Fondo Rodríguez Moure presenta una errata en la fecha: 1975, fecha incorrecta por 1795.

${ }^{21}$ Don Lópe Antonio de la Guerra y Peña, secretario de la Tertulia de Nava y miembro de la Real Sociedad Económica de Amigos del País. Vid. Guerra y Peña, Lope de Antonio de la (1959) Memorias (Tenerife en la segunda mitad del siglo XVIII), Cuaderno IV, años 1780-1791, Las Palmas de Gran Canaria, El Museo Canario.

22 Álvarez (2008, p.251); Guimerá (1979, p.314); Salas (1999, pp.238-239).
} 
obra, corregida y comentada, así como una traducción que la acerque al público en general. Hemos añadido algunas notas explicativas al texto atendiendo a una serie de datos documentales sobre el contenido del poema. En la edición del texto latino hemos optado por un aparato crítico negativo y hemos modernizado grafías y puntuación.

Illustrissimo ac Dilectissimo D.D. Antonio de Tavira et Almazan, Canariensi Episcopo, Tertia decima Junii Sancti Antonii festiva die. Hoc carmen humillime offert Bernardus Cologan Fallon, ut Studia litteraria iam Regio concessa Decreto his in Insulis promoveat foveatque. Anno Domini M.DCC.XCV

Nonne vides ut laeta suum Gens Gallica Regem

Franciscum celebrans, magni det Principis ultro nomina, Franciscique ferant monimenta, ferantque

$5 \quad$ An veteres Heroa vocant, partasve favente Marte canunt lauros? An victis hostibus ulla intrepidum signant Victorem Castra vel Urbes? Strenuus ille fuit, sed non praestantior armis. Novimus, Hispani, Pavianaque Castra, refertis

10 adversam Galli sortem, nostrique secundam! Ecce tamen cunctas Famae tuba personat aures atque viri studiosa canit memorabile nomen. Ipsa virum tantis cur Europa laudibus effert? Cur et amare iuvat, genuit quem Gallia Regem?

15 Scilicet implicitas agresti cortice mentes tunc etiam implebat tenebrarum turpius omen, errorumque genus Natura ruebat in omne, indocta atque ferox cultu. Verum ille suorum Rex magnus vires superans ac temporis ipse

20 quinimo Victor, divino et numine plenus, ingenium cunis fovit, manibusque paternis nascentis docuit titubantes figere gressus; vere novo, veluti dulci cum lumine tandem marcentes recreat camporum Phoebus honores;

25 Quin et tot steriles agros, tot praedia dudum arida vivificans radiis, uberrima reddit.

Sic, Sol ille novus, mentesque animosque suorum protinus e sterili rapiens, longosque per annos obscura vita claram dat vivere lucem.

$30 \quad$ Hinc dixere patrem meritis cum laudibus omnes quas Pater instituit, Franco sub littore, Musae. Hinc etiam egregiae tanti se principis artes nomine condecorant, vatesque et Pictor amicis Aeternam chartis iusserunt vivere famam.

35 Huius ab illustri decurrit origine fontis Gallica doctorum series immensa laborum; 
nec tantum illa suo gens sese turgida iactat

Maecenate: suos habuit Germania docta ingenii Patres, et patres Anglia multos,

$40 \quad$ Anglia praeclaris semper ditissima Musis.

Et mediis, tu, quae memorandae aetatis in annis

praecipue florebas laeta Hispania sorte,

tu, dum alias inter languerent torpius artes

egregiae, patres meritis cum laudibus ultro

$45 \quad$ Nonne tuos celebrasti, opibus quoque turgida tantis?

Usque manus plaudis lugenda morte, cavatis quae fossis Musas veluti rapuere, sepultas dudum saxa inter vetusta, tuisque renatas (Dulce ministerium!) tandem posuere sub oris!

$50 \quad$ Magna, tuum non ${ }^{23}$ Urbanum, tantosque virorum quos veneror, Manes fraudabo laudibus altis Italia, o tu, quae toto ditissimus Orbe Hortus eras, gremioque fovebas una Minervam. Illa renascentes tandem melioribus annis

55 instituit Musas, Musarumque inclyta Templa materno studuit paulatim condere sumptu. Tumque suos fudit fontes, velut amnis ab altis montibus, Ingenium Terrarumque omnia lymphis faecundis dictans, mortalibus attulit artes:

60 Hinc se mille novae, rupta caligine, luces obiecere oculis: hinc et felicior aetas: hincque nova didicit magnum cognoscere vita Omnipotentis opus, viresque Adameia Proles, omniferas, tacitosque per altas aetheris ${ }^{24}$ arces

65 naturae modulos, studio certante, canentis terrigenae passim sobolis celsaeque Parentem. At cunctas subito gentes mutatio tanta non subiit, veluti cum circumdantibus atris nubibus, obscuramque diem paucisque videndos

70 dat radios, moderans dulcissima lumina Titan. Haud secus ille intus qui mentes excutit ignis, et maiora iubet, studio certante, tueri, scrutarique ignota, animumque domare rebellem, vim lentam stimulus venis alit, atque fovere

75 non una multos amat: unde potentia maior. Et nos sylvestres fuimus, longosque per annos fovimus agrestes humano in corpore mentes. Barbara sors nostros, fusa caligine passim, obscurabat avos, donec praeclarior aetas ${ }^{25}$

\footnotetext{
23 non: ego ms.

24 ceteris : aetheris $\mathbf{A A .}$

25 aetas : cetas edd.
} 
conscia nascentis paulatim luminis omen arripuit, necdum diffusae turpe fugarat desidiae velum; rectarum vera viarum semina quin nostris in mentibus orta ferebat sponte sua Natura; sed illius instar agelli,

85 qui felix frustra pandit gremium, atque sine ullo ipse videt cultu, spretos et deflet honores, sic et, nos inter, veluti natura decoras contemptas deflebat opes, quas prodiga passim per campos, docilesque ardebat spargere mentes.

90 At tamen iratam iam iam spes blandula dulci omine delectat, maternosque obvia ${ }^{26}$ risus suscitat Ingenii Proles, studii alma Cupido, quae per torpentes paulatim serpere mentes incipit, et letho similem perrumpere somnum.

95 Namque tuis quantum debetur, Recta Cupido, motibus omniferis! Quantum nova et abdita rerum perscrutari arcana iubes! Quot et undique natos Ingenii partus, te praecipiente, stupemus!

Nec nostros inter longis dominatur ab annis;

100 en tamen intentis inspirat mentibus ignes hactenus ignotos: iam partu namque libenti natum erat ingenium; sed Naturae aemula nondum vixerat ars, et si vixisset, quanta feraci insula quaeque sinu prodigia sponte creasset!

105 Arte favente, fuit iam celsa Nivaria felix: Nonne suum dono (*)27 vatem dedit illa Matrito? Nonne diu versus legit nostra aula iocosos? Nuncque legit, Vatesque legunt praecepta Magistri. Nec plures memorem, decus immortale feracis ${ }^{28}$

110 atque ornamentum Patriae; sic semina recta cum Natura bonae propinat dulcius arti, haec memor aequato respondet munere victrix. Nec satis: imperfecta diu se conficit uno res velut assensu: Collegia nulla vocabant

115 ad studium iuvenes: optatam nulla fovebat ${ }^{29}$ Parnassi errantis Domus ad certamina pacem. maternos Patria effundit de pectore questus; exilio veluti turpi, sine lege vagantes, inclamant Musae; ...Sed flebilis ipse Cohortis

120 Carolus abstergit lacrymas, optataque sumptu imperat esse suis Collegia facta paterno.

\footnotetext{
26 obvia : obvia AA ${ }^{\text {post corr }}$ obviat edd.

27 (*) Iriarte (Nota manuscrita).

28 feraces: feracis $\mathbf{A A .}$

${ }^{29}$ fovebat: fovebant $\mathbf{m s}$.
} 
Tu potius Deus, alme Deus, dulcissima nostras ad miseras etiam convertis lumina rupes! Nam rupes idem, et pulcherrima respicis arva, 125 Regalesque Domos, misero et Magalia cultu. In magnis timidus veluti cum flosculus hortis, maiorum quamvis vel distet ab agmine florum, captat ${ }^{30}$ Heri tamen assiduum miserantis amorem, Tu quoque noster eris, tu, dilectissime Praesul,

130 Franciscus: tibi Decretum Regale potentes dat Regis partes: Collegiaque ordine recto constitues, et nostra implebis vota, precesque: tu patriae Pater alter eris, praeclarior illo Patre, fero veteres qui vicit Marte Colonos

135 innocuos, ac Hispanae dedit esse Coronae. Non ferro vinces, non exitialibus armis, ingenium, arma tibi, ratio, non ferreus ensis. Non tibi quas memori dextra sponte Insula quaeque prona dabit, Lauros profuso sanguine partas,

$140 \quad$ sanguine non tinctas, pretium nec triste cruoris humani, impones capiti ornamenta cruento; offeret at quales viridi Natura colore procreat innocuis Lauros mortalibus ultro. Nec satis; in nostris surgent tibi mentibus arae 145 arae, non stultum, grati sed pignus amoris! Non monimenta quidem tangentia celsa superbis sidera verticibus: quin et monimenta voraci evertit Tempus Falce, atque cacumina Terrae alta aequat laevi, gravium et vestigia rerum $150 \quad$ vix superesse sinit, flecti ullis nescius hostis humanis precibus. Nostris at mitior aris parcet, et ardebunt memores tua dicere proli nomina certatim patres, Prolesque Futuris. Iam nec erit solis natos bene cura docendi 155 patribus, en dulcis sobolem altera Mater amabit, doctos indoctosque gravi iam pondere patres eximet, atque bonas sponte informabit ad artes, aequa, piosque gerens mores, moresque severos. Ipse ego, si vires Deus, ac cum numine voces

160 det mihi, conabor iuvenili carmine laudes bisque iterumque tuas pro tantis dicere factis. Nec mea (ne credas) verba haec expromere nitor, stultus adulator: fallaces usque biformis ipse aulae laudes, mellitaque verba refugi.

165 Hos mihi sed versus patriae inspirare laborat

\footnotetext{
${ }^{30}$ captat $:$ capta $\mathbf{m s}$.
} 
verus amor, qui cuncta rudes per saecula vates movit, et ignotis incendit pectora flammis. Me movet illa animis spes iucundissima nostris, ingenuae ut sedeant istis in rupibus artes;

170 quin et, (si liceat festivis vocibus uti Parnassi) ut quae regna colit viridantia Bacchus dives opum, ipsa colat meliori lege Minerva. Sic velut Hortus, erunt, ubi mollia poma palatum non solum saturant, viridi sed lumina vultu

175 exhilarant; sic et miscebunt utile dulci.

Eia, age, propositis tandem quaeso annue coeptis ${ }^{31}$, bisque iterumque precor, simili te voce precantur concives, studiique arrecta cupidine turba: doctrinae, exclamant, saxis aeterna sub aptis

180 fundamenta loca, sensimque novo aggere crescet alta Domus, longos stimulo servanda per annos. Et tibi, nec dubito Collegia condere nostra magnae molis erit; maioris, semina veri ingenii excusso mendacis spargere fuco.

185 Hinc melius nobis erit; hinc tibi gloria maior. Namque creator eris; formabisque omnia recto iudicio, puros inspirans mentibus ignes. Ipse potes; nec enim Franciscis sola potestas cuncta reformandi; Te, Antoni, magna sequetur

190 Fama, omnique tuum vivet sub pectore nomen. Haecque dies memorat natum melioribus annis, nomine laeta tuo celebrat quem Ecclesia sanctum, quique sui memorem factis insignibus Orbem fecit, doctrinaque simul, pietateque clarus.

195 O! utinam laudes depingere carmine possem ipse tuas hodie! ... fugies sed thura Poetae nobilis ${ }^{32}$ Orator; Phoebum facunda Minerva saepe fugit, parvis nec certant flumina rivis se immiscere, Rosis nec Regia Lilia cedunt.

$200 \quad H o s$ tamen ecce tui versus incensus amore scripsi, vetusto quos more haec festa diurna produxere, at non invito pectore partos.

Haec humili metuens tibi do munuscula ${ }^{33}$ dextra, accipe, quaeso, eheu! torpi ceu languida somno

205 Musa diu siluit! Plausu si carmina credis digna tuo, ipse tibi plaude; altos namque iacentis tu solus Musae potuisti abrumpere somnos.

\footnotetext{
31 coeptis : ceptis edd.

32 nobilis : nobili $\mathbf{m s}$.

33 munuscula : monuscula AA.
} 


\section{TRADUCCIÓN AL CASTELLANO}

Al ilustrísimo y muy apreciado don Antonio de Tavira y Almazán, obispo de Canarias, a 13 de junio, festividad San Antonio, Bernardo Cólogan Fallon le dedica este humilde poema para que promueva y favorezca en estas Islas los estudios literarios ya aprobados por el Real Decreto ${ }^{34}$. Año 1795.

¿Acaso no ves cómo la nación francesa, celebrando contenta a su rey Francisco 35 , extiende su fama de gran príncipe, se levantan monumentos en su honor y se acuñan monedas grabadas con su grato nombre? ¿Acaso los antiguos no aclaman a su héroe, o no celebran los triunfos conseguidos con el favor de Marte? ¿Acaso algunos Campamentos o Ciudades, vencidos los enemigos, no enaltecen al intrépido Triunfador? Aquél $^{36}$ fue valiente, pero no más hábil con las armas. Lo sabemos nosotros, los españoles, y también los campamentos de Pavía ${ }^{37}$ : Vosotros, los franceses, habéis llevado una adversa suerte, y los nuestros una favorable. He aquí, sin embargo, que el clamor de la Fama retumba en todos los oídos y, propicia, canta su célebre nombre. ¿Por qué la propia Europa lo ensalza con tantas alabanzas? ¿Por qué agrada querer a quien Francia nombró rey ${ }^{38}$. Sin duda, entonces, un oscuro presagio de tinieblas llenaba las mentes enredadas en una dura envoltura y la Naturaleza, indocta y de índole salvaje, se precipitaba en todo tipo de extravíos. Pero aquél gran rey ${ }^{39}$, superior en fuerza a los suyos, antes bien dominador del momento y lleno de una inspiración divina, rodeó de cuidados en su primera infancia el talante de las tropas y con manos paternales enseñó a plantar los vacilantes pasos del recién nacido; así como Febo, al comienzo de la primavera, con un dulce rayo de luz finalmente renueva las galas marchitas de los campos, más aun, dando vida con sus rayos a tantos campos estériles, a tantas tierras desde hace tiempo áridas, los torna fecundos. De la misma manera aquel nuevo $\mathrm{Sol}^{40}$, arrebatando las

\footnotetext{
${ }^{34}$ Como ya apuntábamos, Bernardo Cólogan Fallon compuso estos versos con motivo del encargo de establecer la Universidad que había sido encomendado al obispo don Antonio Tavira. Con anterioridad, el obispo había recomendado el establecimiento de un centro superior de enseñanza, aprobado en el Real Decreto del año 1792, por el que se confirmaba la creación de la Universidad en la ciudad de La Laguna, capital en ese momento de la isla de Tenerife, por las ventajas de su situación (Escobedo 1938, pp.18-19, 122 s.; Salas (1999, pp.115-120, 238, 142-143). Cf. Galván (2010, p.187): «No en vano la razón de su nombramiento regio para Canarias es la realización de las gestiones pertinentes para la creación de una universidad en Canarias, a instancias de Campomanes y por el aval del plan de reforma que este le encargó para la Universidad de Salamanca en 1767. El 11 de marzo de 1792, por un Real Decreto de Carlos IV, se fundó la primera universidad literaria de las Islas, aunque no pudo desarrollar su actividad con normalidad por la convulsa situación política para ser restablecida el 12 de enero de 1817. Las aportaciones de Tavira para el Seminario Conciliar, no obstante, fueron decisivas para la mejora pedagógica de la institución».

${ }^{35}$ Francisco I, rey de Francia.

${ }^{36}$ El autor se refiere de nuevo a Francisco I, rey de Francia.

${ }^{37}$ La batalla de Pavía (1525) fue una contienda mantenida entre el ejército francés al mando del rey Francisco I y las tropas germano-españolas del emperador Carlos V, con victoria de estas últimas, en las proximidades de la ciudad italiana de Pavía.

${ }^{38}$ Francisco I obtuvo una victoria mayor que la del vencedor, la fidelidad incondicional de su pueblo. Cólogan nos hace ver que este patriotismo a toda prueba era, sin duda, un motivo de orgullo para el monarca francés, un triunfo moral compensatorio de la derrota sufrida.

${ }^{39}$ Francisco I, rey de Francia

40 Se refiere de nuevo a Francisco I, rey de Francia.
} 
mentes y los ánimos de los suyos de una vida constantemente estéril y oscura durante largos años, les permite vivir una resplandeciente luz. Por una parte, todas las Musas lo llamaron padre con merecidos elogios que él consiguió al pie del litoral francés. Por otra, las ilustres artes se embellecen con el nombre de tan gran príncipe, y tanto el poeta como el pintor desearon vivir una fama eterna en los placenteros escritos ${ }^{41}$.

Del ilustre origen de esta fuente parte una gran tradición gala de sabios trabajos. Y no sólo aquél pueblo se jacta orgulloso de su Mecenas. La sabia Germania tuvo sus Padres de la inteligencia, también Inglaterra muchos, Inglaterra, siempre muy abundante en brillantes Musas. Y tú, España, que en los años centrales de una época memorable ante todo florecías por tu buen hado, tú, mientras entre otras artes palidecían torpemente las ilustres, ¿acaso no celebraste a tus padres con merecidos elogios, orgullosa también por tan grandes obras? Sin cesar bates las manos a causa de la deplorable muerte, tras excavar fosas que arrebataron a las Musas, sepultadas por decirlo así desde hace tiempo entre viejas piedras, $\mathrm{y}$, finalmente, las depositaron renacidas bajo tus orillas! (¡A gradable menester!). No defraudaré con grandes alabanzas las almas de los personajes ilustres ni a tu Urbano ${ }^{42}$ y a tantos hombres a los que saludo con veneración, oh tú, gran Italia, que eras el Jardín más preciado en todo el orbe y que sola tenías en tu regazo a Minerva. Ella instruyó a las Musas para renacer finalmente en tiempos mejores y se esforzó en erigir los insignes Templos de las Musas con maternal dispendio.

Derramó entonces sus fuentes, como el río desde los altos montes, y disponiendo el Ingenio y todas las cosas de la Tierra en las aguas fecundas, enseñó las artes a los mortales: de aquí, despejada la oscuridad, aparecieron ante los ojos un millar de nuevas luces; de aquí también la época más feliz; de aquí una vida nueva, la prole de Adán, aprendió a conocer la gran obra del Omnipotente, y las fecundas fuerzas, y, por las altas cimas del cielo, las silenciosas melodías de la naturaleza, que, con gran empeño, canta por doquier al Padre de la estirpe terrenal y celestial. Pero un cambio tan grande no llegó de pronto a todos los pueblos, como, cuando en medio de negras nubes, Titán, moderando su dulce resplandor, permite que unos pocos puedan ver los rayos y la oscuridad del día. No de otra manera que aquel fuego desde dentro golpea las mentes y ordena contemplar lo más grande con empeño, descubrir lo desconocido y subyugar el espíritu indómito, un estímulo alimenta una lenta fuerza en las venas y no ansía favorecer a muchos a la vez; de ahí una mayor fuerza. También nosotros fuimos salvajes y por muchos años alimentamos mentes incultas en un cuerpo humano. Disipada por doquier la oscuridad, una bárbara condición oscurecía a nuestros antepasados, hasta que una edad más noble, consciente de la luz que nacía poco a poco, detuvo el augurio y ni siquiera así el torpe velo de la dispersa desidia desaparecía; más aún la Naturaleza voluntariamente no ofrecía las verdaderas semillas de los rectos caminos sembradas en nuestras mentes, pero, a semejanza de aquel pequeño campo, que feliz en vano

\footnotetext{
${ }^{41}$ En estas líneas (vv.13-33) Francisco I aparece descrito como un soldado-poeta, motivo de admiración para nuestro autor, quien, valiéndose del conocido tópico literario, no duda en compararlo con la figura del obispo. Podríamos decir, incluso, que el propio Cólogan corresponde a esta figura. Podríamos describirlo con una espada en la mano luchando contra los ingleses, ayudando a un enemigo herido o, como diría Garcilaso, «tomando ora la espada ora la pluma».

${ }^{42}$ El papa Urbano VIII (1623-44), mecenas de grandes artistas y protector de las ciencias y las artes, fue un papa sumamente ilustrado, teólogo, astrónomo, literato y amigo de las nuevas ideas (Beltrán 2006, p.38; Miranda 2007, pp.165-184).
} 
muestra su regazo y lo ve sin ningún cultivo, y suspira por los desdeñados honores, así, también, entre nosotros, la naturaleza añoraba hermosas riquezas descuidadas, a las cuales pródiga deseaba de nuevo esparcir por doquier en los campos y las dóciles mentes. Sin embargo, a ella irritada la dulce esperanza ya la deleita con grato presagio $y$, yendo a su encuentro, suscita risas maternales la estirpe del Ingenio, Cupido, nutricia de la pasión ${ }^{43}$, que poco a poco comenzó a extenderse por las confusas mentes y a infundir un sueño similar a la muerte. Pues ¡cuánto se debe, Recta Cupido, a tus fecundos deseos! ¡Cuántos secretos nuevos y escondidos ordenas descubrir! ¡De cuántos y diseminados hijos nos maravillamos frutos del ingenio, según tus deseos! Entre los nuestros no reina desde hace muchos años. Sin embargo, a las mentes despiertas inspira pasiones hasta hoy desconocidas; ya el ingenio había nacido en un parto placentero, pero el arte, imitador de la Naturaleza, aún no había nacido, y, si hubiera existido, qué isla ${ }^{44}$ por propia voluntad no hubiese creado todos los prodigios en su fértil regazo! Con la ayuda del arte la sublime Nivaria ${ }^{45}$ fue próspera ¿Acaso ella no dio su propio vate $^{46}$ como regalo a Madrid? ¿Acaso no leyó durante largo tiempo versos festivos en nuestro palacio? Ahora los sigue leyendo y los Vates leen los preceptos del Maestro. No voy a mencionar a muchos, honor imperecedero y gloria de la fecunda patria. Así, como la Naturaleza dulcemente concede fructíferas semillas al buen arte, consciente de estas cosas, responde victoriosa con un don similar. Y no le basta con ello: se lleva a cabo un asunto inacabado durante tiempo con un solo consenso: a los jóvenes ningún Colegio llamaba al estudio. Ninguna Casa del errante Parnaso favorecía la paz deseada para los certámenes. La Patria vierte del pecho maternales lamentos; las Musas, que sin ley vagan, claman en un vergonzoso exilio;... Pero el propio Carlos, afligido, enjugó las lágrimas de su cohorte y ordena que los ansiados colegios se hagan para los suyos a expensas propias. ¡Tú, Dios Todopoderoso, venerable Dios, conviertes las muy dulces luces en nuestras tristes rocas! Pues roca tú mismo, no sólo vuelves a mirar los campos más fértiles, y las Casas Reales, sino también las Chozas de poca cultura. Como cuando en los grandes prados la tímida florecilla de los mayores, aunque se diferencia de la multitud de flores, trata de ganar, sin embargo, un verdadero amor al triste Ayer, también tú, Francisco, tú serás nuestro amadísimo Obispo ${ }^{47}$. El Decreto Real te concede poderosas funciones del Rey: crearás Colegios con buen juicio y colmarás nuestros deseos y súplicas. Tú serás un segundo Padre de la patria, más insigne que aquel Padre ${ }^{48}$ que venció a los antiguos Colonos indefensos con violenta guerra y la concedió a la corona de España; no vencerás con la espada, ni con armas mortales

\footnotetext{
43 Cupido o el amor como figura femenina aparece con frecuencia en textos medievales, en los que Venus y Cupido -así como sus atributos- son perfectamente intercambiables (Llamas 2005).

${ }^{44} \mathrm{El}$ autor se refiere a la isla de Tenerife.

45 Nivaria (Ninguaria o Niguaria): topónimo atribuido a Tenerife por Plinio en el s.I d.C. (Historia natural, libro VI, 37, 198-205). Cf. Martínez (1996, p.151 s.); (2010, p.7); Real (1998, p.618 s.).

$46\left(^{*}\right)$ Iriarte (Nota manuscrita). Se refiere a Tomás de Iriarte (1750-1791), poeta español de la Ilustración y el Neoclasicismo nacido en el Puerto de la Cruz (Tenerife), que desarrolla su labor literaria en Madrid junto a su tío Juan de Iriarte, aunque también cabe la posibilidad de que aluda a éste último gran humanista portuense. Cólogan en un ejemplo de exaltación insular destaca la predisposición de esta tierra para dar frutos ilustres.

${ }^{47}$ Se refiere Cólogan a don Francisco Xavier Delgado y Venegas, obispo de Canarias (1761-1768). Cf. Guimerá (1979, p.314).

48 Posible referencia al Adelantado, Alonso Fernández de Lugo.
} 
al ingenio, para ti las armas son la razón, no la espada de hierro ${ }^{49}$. No te dará la Isla ${ }^{50}$ entera de buen grado para tu recuerdo aquellas coronas de laurel que, logradas con derramamiento de sangre, no teñidas de sangre, y no como triste precio de sangre humana, tú impondrás a una cabeza sangrienta, sino que te ofrecerá las que procrea con verde color la Naturaleza para los inofensivos mortales. Y no basta con esto ¡en nuestras mentes surgirán para ti altares, altares, no una prenda necia, sino la propia de un amor agradecido! En verdad, no monumentos que tocan las altas estrellas con sus altivos vértices, ni tampoco monumentos que el paso del tiempo destruye con su voraz hoz e iguala las altas cimas de la escarpada Tierra, y apenas permite que permanezcan las huellas de grandes hechos, ni sabe conmoverse ante ninguna súplica humana del enemigo. Pero más moderado sentirá respeto por nuestros altares $\mathrm{y}$, en verdad, los padres que recuerdan estarán ansiosos por dar tu nombre ${ }^{51}$ a sus hijos, y vuestros hijos a los que les sucederán. Ya ni siquiera los padres tendrán solos el cuidado de enseñar bien a sus hijos. Y he aquí que otra Madre dulcemente amará a su estirpe, librará a los padres sabios e ignorantes de una pesada carga, enseñará por voluntad propia lo adecuado para las buenas artes, siguiendo hábitos piadosos y costumbres severas.

Yo mismo, si Dios me da fuerzas y palabras convincentes, intentaré una y otra vez narrar tus glorias por tantas hazañas en un poema juvenil y -no creas- no trataré de demostrar estas palabras mías, necio adulador: yo mismo huí de falsos elogios y palabras lisonjeras de una falsa corte. Pero el verdadero amor me inspira estos versos a la patria, el cual mueve a los rudos vates a través de todos los siglos y enciende con pasiones desconocidas los corazones. Aquella esperanza tan feliz para nuestros espíritus me hace creer que las artes puras permanecen en estos peñascos ${ }^{52}$; es más (si es lícito hacer uso de las palabras festivas del Parnaso) qué los fecundos reinos que Baco, rico en recursos, cultiva, esos mismos Minerva los cuide con mejor tino. Así como el Jardín, permanecerán, donde tiernas frutas no sólo sacian el paladar, sino que alegran los ojos con verde semblante; así mezclarán lo útil con lo dulce. ¡Ea pues, te ruego, favorece mis propósitos, te lo suplico una vez más y con insistencia -a voces te lo imploran los conciudadanos-, y la multitud animada por el afán de estudio!: Enseñanzas, exclaman, eternos cimientos bajo piedras adecuadas, y paso a paso crecerá en un nuevo cúmulo la Casa $\mathrm{Alta}^{53}$, que ha de ser guardada con cuidado por muchos años. Y para ti, no lo dudo, será de gran importancia fundar nuestros Colegios; de mayor importancia esparcir las semillas del verdadero talento con un adorno desprovisto de falsedad. Será lo mejor para nosotros, para ti mayor será la gloria. Pues serás el fundador y harás todas las cosas con buen juicio, inspirando a las mentes sentimientos puros. Tú puedes, pues no fue suficiente la sola voluntad de Francisco de cambiarlo todo. A ti, Antonio, te acompañará una gran Fama y tu nombre pervivirá en todo corazón. Este día conmemora tu onomástica ${ }^{54}$ en años felices, a la que con tu nombre la Iglesia santifica dichosa, y quien, ilustre, a la vez, por su sabiduría y piedad, hizo por sus grandes obras que de

\footnotetext{
49 Aparece Tavira como un héroe cultural, el «Francisco de los canarios», el ilustrado que defiende la razón y denosta el uso de la espada.

50 Tenerife.

51 Se refiere al obispo Tavira.

52 Alusión a la orografía montañosa de la isla.

53 Se refiere el autor a la tan ansiada Universidad.

${ }^{54}$ El día de San Antonio, 13 de junio, santo del obispo Tavira.
} 
él se acordase el Orbe. ¡Ojalá pudiese hoy describir en un poema tus proezas!, pero tú, célebre Orador, huirás de los inciensos del Poeta; a menudo la elocuente Minerva huye de Febo, los ríos no luchan por mezclarse con pequeños riachuelos, ni los Regios Lirios ceden ante las Rosas. He aquí que, llevado por el afecto, he escrito estos versos, que según la antigua costumbre promovieron estas celebraciones del día de hoy, motivados de todo corazón. Por temor a estas cosas te doy con humilde diestra este pequeño obsequio, recíbelo, te lo ruego! ¡ay! ¡Es así que la Musa calló hace tiempo abatida por un funesto sueño! Si consideras el poema digno de tu gusto, felicítate a ti mismo; pues solo tú pudiste interrumpir el profundo sueño de la lánguida $\mathrm{Musa}^{55}$.

\section{EPÍLOGO}

Con la edición de este texto perseguíamos poner al alcance del público parte de la producción inédita de Bernardo Cólogan Fallon y completar así la escasa información que teníamos sobre su labor literaria.

El elogio que Cólogan hace a la figura y la labor del prelado se enmarca en la poesía circunstancial dieciochesca de raigambre ilustrada, donde abundaban los poemas dedicados a algunos de los obispos canarios con inquietudes literarias (Galván 2010, p.189; Salas 1999, p.233). Sus versos se hacen eco del trasfondo histórico de la época al citar una serie de acontecimientos de gran importancia, tales como la guerra de Pavía y la derrota de los franceses con la consiguiente victoria de los españoles ${ }^{56}$. Así inicia Cólogan su composición con la descripción de Francisco I, rey de Francia, la persona que contribuye al restablecimiento y propagación de las bellas letras, razón por la cual fue llamado grande y vio dilatada su fama, a pesar de no haber sido afortunado en la guerra. Aparece Tavira como el «Francisco de los canarios», el ilustrado que defiende la razón y denosta el uso de la espada ${ }^{57}$. Asimismo, Cólogan utiliza con habilidad imágenes alegóricas, mitológicas y analogías para presentar a Tavira como un nuevo Febo, dios del Sol y de la luz, que viene a disipar las sombras de la ignorancia. También el texto deja entrever algunos tópicos (miscebunt utile dulci, v.175) y metáforas (Mater=Iglesia) muy utilizados en la literatura clásica y en la humanística.

Es una pieza elaborada con palabras llenas de intención, de cuya lectura se deduce un conocimiento importante de la literatura latina donde encontramos similitudes con la epopeya en el uso del metro, en la narración de hechos memorables y en el tratamiento de la figura de un héroe, Tavira, que representa sus mayores virtudes por su extraordinario apoyo a las artes y la cultura.

\footnotetext{
55 Con esta especie de captatio benevolentiae, el autor intenta modestamente ganarse el favor del obispo, descrito en estos versos como el salvador que vendría a sacar a las Islas de su ignorancia.

${ }^{56}$ La guerra entre Francia y España que estalla a finales de la centuria paralizó por un tiempo la creación de la Universidad, mitigando las rivalidades de las dos islas por su posesión. Cf. Salas (1999, p.144).

57 «Tu patriae pater altis eris, praeclarior illo/ Patre, fero veteres qui vicit Marte Colonos/ innocuos, ac Hispanae dedit esse Coronae./ Non ferro vinces, non exitialibus armis, / ingenium, arma tibi, ratio, non ferreus ensis» (vv.133-137).
} 
El estado deplorable de los estudios en Canarias y la decadencia de las escuelas parroquiales llevan a Cólogan a denunciar un hecho evidente en aquella época: el penoso olvido en el que estaban sumidos los estudios canarios. Esta actitud nostálgica se dirige hacia el recuerdo de una edad heroica que determina en quien la contempla la proyección hacia un tiempo pasado que fue mejor.

Es también un poema que surge al calor de sus inquietudes cívicas e intelectuales, donde el prelado resolverá la lucha de ascendencia clásica entre Ingenium y Natura, las luces que traen las bellas artes frente a la oscuridad de la ignorancia. Podemos afirmar que sus versos son la expresión de las convicciones y valores de un hombre cultivado, un ejemplar típico del español del siglo XVIII que militaba en el campo de la Ilustración en plena transición hacia el Romanticismo, con el rostro vuelto hacia Francia y las mejores ideas de engrandecimiento interno de su ciudad en la mente ${ }^{58}$. Esto le lleva a aunar sus esfuerzos a los de Tavira en empresas de desarrollo cultural de las islas. Como hemos señalado, el obispo es para nuestro autor fuente de inspiración y un modelo digno de imitación por su trayectoria como portavoz de la cultura ilustrada, por lo que podemos afirmar que esta composición persigue claramente ensalzar uno de los principales objetivos del reformismo ilustrado: la educación.

La utilización del paisaje canario como escenario de la batalla luz/oscuridad se concreta con la alusión a Nivaria y a su orografía agreste. Una velada alusión al Teide, motivo poético por antonomasia de nuestros líricos, recrea el caos que será ordenado por las musas con la llegada de Tavira a las Islas.

En resumen, el poema en cuestión constituye una pieza literaria de indudable valor. Por un lado, está su valor literario como poesía de circunstancia, y, por otro, tiene un valor histórico, ya que Cólogan se inspira en la realidad que le circunda, un testimonio fidedigno en la historiografía canaria por ilustrar, asimismo, la rápida adaptación de familias extranjeras a la vida insular y su participación en la política del momento. La pervivencia del mundo clásico en estos versos, finalmente, no sólo debería adquirir un valor cultural y humanístico importante, sino también debería ser útil para entender mejor la idiosincrasia del momento.

\footnotetext{
${ }^{58}$ Cf. Guimerá (1979, p.315): «Es muy reciente la memoria del malhadado Cólogan para que toda la presente generación no llore la temprana muerte del sabio y discreto amigo de Talia y Melpómene; y estoy persuadido que si su salud, negocios de su largo comercio, y mejor suerte en sus amores hubieran dejado encender tranquila su hoguera poética, el Teide hallase en él su Pindaro u Horacio vengador, si no en el idioma del cantor de la Flor de Gnido, del de las ruinas de Itálica, del Joven de Austria, de la Profecía del Tajo o de otros célebres modernos, a causa de su educación en países extranjeros, a lo menos en el de aquel que pintó el Atlas soberbio, y a Mercurio alado volando sobre su corona de verdes pinos, de los ríos corriendo por su barba y ésta con eternas nieves, y de los imitativos sublimes versos de los mugidos horrorosos del Etna siciliano; o de Triphón gigante, en su centro revolviendo su encendida espalda; lanzando su llama arrebatadora, que lame las estrellas Es preciso haberle conocido para calcular el tamaño de la pérdida y para no maldecir eternamente las causas de su prematura ruina.
}

Varium ac inmutabile

Semper faemina .

Fuerza, lenguaje, harmonía estudiada, delicadeza, todo acompañaba y formaba el carácter de este poeta, ministro de Temis». Cf. Millares (1987, p.29). 


\section{REFERENCIAS BIBLIOGRÁFICAS}

Álvarez Rixo, J.A. (1994), Anales del Puerto de la Cruz (1701-1872), Santa Cruz de Tenerife, Cabildo Insular de Tenerife.

Álvarez Rixo, J.A. (2008), Noticias biográficas de algunos isleños canarios, Santa Cruz de Tenerife, Las Palmas de Gran Canaria, Ediciones Idea, Colección Estudios Hispánicos.

Barrios Gonzalo, M. (2002), «Estudio socioeconómico de los obispos de Canarias durante el Antiguo Régimen (1556-1834) », AEA 48, pp.413-481.

BeLtrÁn MARí, A. (2006), «Galileo y Urbano VIII. La trama del equívoco», ÉNDOXA: Series filosóficas 21, pp.35-73.

Cazorla, S. - SÁnchez, J. (1997), Obispos de Canarias y Rubicón, Madrid, Editorial Espasa.

Cólogan Soriano, C. (2010), Los Cólogan de Irlanda y Tenerife (1684-2010), Santa Cruz de Tenerife, Islas Canarias.

Domínguez Ortiz, A. (1989), Carlos III y la España de la Ilustración, Madrid, Alianza Editorial.

Escobedo, J. - Alberú, G. (1938), La Universidad de Canarias. Apuntes para su historia desde su primera fundación en 1701 hasta el presente, Madrid, Librería General de Victoriano Suárez.

GALVÁN GonZÁLEZ, V. (2010), «La literatura y la cultura canaria durante el reinado de Carlos IV (1788-1808) », Cuad. diecioch. 11, pp.179-205.

GueRra y PeÑA, L.A. DE LA (1959), Memorias (Tenerife en la segunda mitad del siglo XVIII), Cuaderno IV, años 1780-1791, Las Palmas de Gran Canaria, El Museo Canario.

Guimerá PerazA, M. (1979), «Bernardo Cólogan y Fallon (1772-1814)», en AEA 25, pp.307355.

Guimerá Peraza, M. (1992), «Los Cólogan, alcaldes del Puerto de la Cruz de la Orotava», AEA 38, pp.199-250.

InFAnTES FloRIDO, J.A. (1979), Figuras de la Iglesia canaria. Tavira (1791-1796). Las Palmas de Gran Canarias, Colección Guagua.

InFANTES FloRIDO, J.A. (1981), Crisis religiosa e Ilustración. Un horizonte desde la biblioteca de Tavira: ventanal sobre la Iglesia del siglo XVIII, Las Palmas de Gran Canaria, El Museo Canario.

Llamas Pombo, E. (2005), «Militat omnis amans. Las guerras de amor en la literatura medieval francesa y su herencia latina», Cuadernos del CEMyR 13, pp.79-112.

Martín Perera, A. - Ramos Arteaga, J.A. - Real Torres, C. (2012), «Cólogan y Tavira: los comienzos de un joven ilustrado», en Actas del XIX Coloquio de Historia CanarioAmericana, Las Palmas de Gran Canaria, Cabildo Insular de Gran Canaria, pp.873-883.

Martínez Hernández, M. (1996), Las Islas Canarias de la Antigüedad al Renacimiento: nuevos aspectos, La Laguna (Tenerife), Las Palmas de Gran Canaria, Centro de la Cultura Popular Canaria.

Martínez Hernández, M. (2010), «Islas míticas en relación con Canarias», CFC (g) 20, pp.139-158.

Millares Carló, A. - Hernández SuÁRez, M. (1987), «Bibliografía de escritores canarios (siglos XVI, XVII y XVIII) », Tomo V, Gran Canaria, Cabildo Insular, con la colaboración de El Museo Canario, pp.313-332. 
Miranda Urbano, C. (2007), «Maffeo Barberini, Urbano VIII ou o Papa poeta», Humanitas 59, pp.165-184.

Ramos Arteaga, J.A. - García Santana, L. (eds.) (2008), La noticia a tiempo: comedia en un acto; Diario de viaje del joven Cólogan, Santa Cruz de Tenerife, Seminario de Estudios Teatrales, D.L.

ReAl Torres, C. (1998), «Las Islas Canarias en el Humanismo: Alfonso de Palencia», en Actas del Congreso Internacional sobre Humanismo y Renacimiento, I, León, Universidad de León, pp.617-624.

ReAl Torres, C. (en prensa), «Del humanismo a la ilustración: Bernardo Cólogan Falon», en Humanismo y Pervivencia del Mundo Clásico V. Homenaje al profesor Juan Gil (Alcañiz, 2010).

RÉGulo Pérez, J. (ed.) (1952-1977), Nobiliario de Canarias, 4 tomos, La Laguna (Tenerife).

Romero RuIz, C. (1991), Las manifestaciones volcánicas históricas el Archipiélago Canario, t. I, Tenerife, Editorial.

Salas Salgado, F. (1999), Humanistas canarios de los siglos XVI al XIX. Tomo I. Contexto histórico-literario. Tomo II. Catálogo bibliográfico, La Laguna, Universidad, Servicio de Publicaciones.

SAlAs SALGAdO, F. (2000), «La enseñanza humanística en el siglo XVIII en Canarias a través de la biblioteca de Antonio Tavira», AEA 46, pp.235-267.

SaugnieuX, J. (1986), La ilustración católica en España. Escritos de D. Antonio Tavira obispo de Salamanca (1737-1807), Salamanca, Universidad de Salamanca.

Universidad de La Laguna, Biblioteca, Catálogo de mss. de la Biblioteca Universitaria de La Laguna, 2002, pp.97-19. 